\title{
Perturbing effects of the probe support on the calibration of electric field meters
}

\author{
O. Bottauscio ${ }^{1}$, M. Chiampi ${ }^{2}$, G. Crotti $^{1}$, and L. Zilberti ${ }^{2}$ \\ 1 Istituto Nazionale di Ricerca Metrologica (INRIM), Strada delle Cacce 91, 10135 Torino, Italy \\ 2 Dipartimento di Ingegneria Elettrica, Politecnico di Torino, Corso Duca degli Abruzzi 24, 10129 Torino, Italy
}

Received: 21 January 2010

Published online: 16 February 2010 - (C) EDP Sciences

Eur. Phys. J. Appl. Phys. 42, 345-350 (2008), DOI: 10.1051/epjap:2008065

An error occurred in Figure 2, page 347 of the original article.

The correct Figure 2 is as below. We apologise for this error.

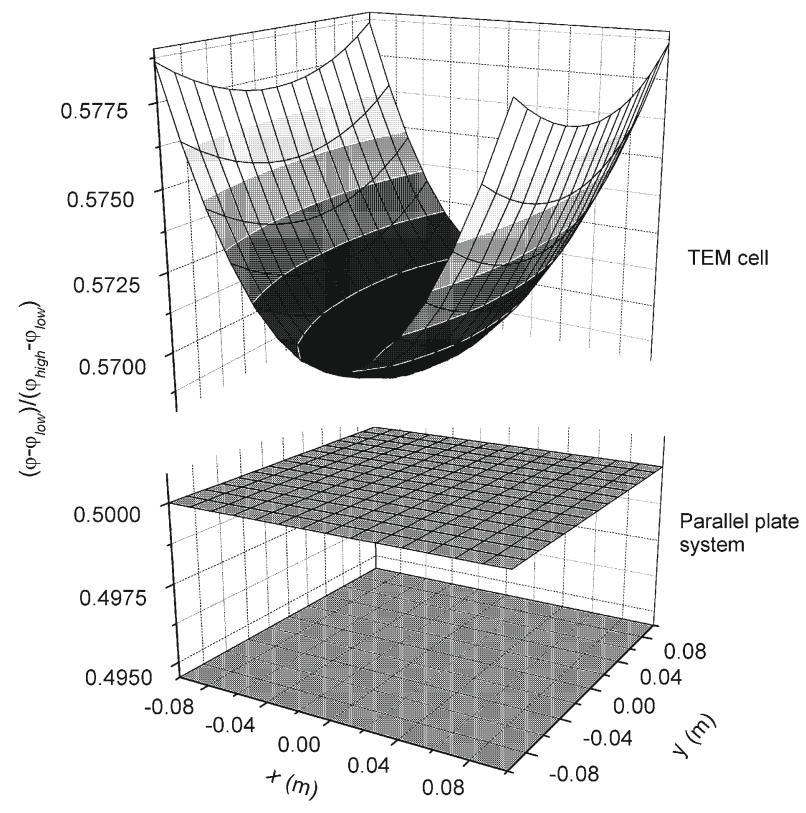

(a)

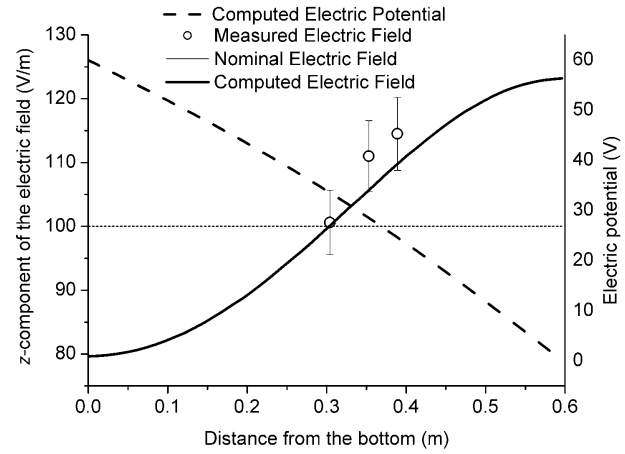

(b)

Fig. 2. Normalized electric potential distribution over a square surface around the system center in the parallel plates and in the TEM cell (a). Potential and electric field distribution along a line between the electrodes in the center of the TEM cell (b). The nominal electric field value is $100 \mathrm{~V} / \mathrm{m}$; the dots are the measured field values. 